SANTOS MRA; TIMBÓ ALO; CARVALHO ACPP; JMORAIS JPS. 2006. Estudo de adubos e substratos orgânicos no desenvolvimento de mudas micropropagadas de helicônia. Horticultura Brasileira 24: 273-278

\title{
Estudo de adubos e substratos orgânicos no desenvolvimento de mudas micropropagadas de helicônia
}

\author{
Maurício R A Santos ${ }^{1}$; Ana L O Timbó ${ }^{2}$; Ana C P P Carvalho ${ }^{2}$; João P S Morais ${ }^{2}$ \\ ${ }^{1}$ Embrapa Rondônia, C. Postal 406, 78900-970 Porto Velho-RO; ${ }^{2}$ Embrapa Agroindústria Tropical, C. Postal 3761, 60511-110 Fortaleza- \\ CE; E-mail: mauricio@cpafro.embrapa.br
}

\section{RESUMO}

Avaliou-se a eficiência de combinações de substratos orgânicos (casca de arroz carbonizada, pó de casca de coco verde e seco) e adubos (Vitasoloâ e húmus de minhoca), em esquema fatorial 3x2, na proporção de 3:1 (v/v), na aclimatização de plântulas de Heliconia bihai, provenientes de cultivo in vitro. Foram estabelecidos contrastes ortogonais, definidos "a priori": pó de casca de coco x casca de arroz carbonizada; pó de casca de coco seco x pó de casca de coco verde; e Vitasolo ${ }^{\circledR}$ x húmus de minhoca. Após 75 dias, avaliou-se a altura das plantas, o diâmetro do pseudocaule, o número de folhas e a área da terceira folha. Em relação a todas as variáveis estudadas, a casca de arroz carbonizada foi mais eficiente do que o pó de casca de coco; o pó de casca de coco verde ou seco não diferiram significativamente entre si; entre os adubos testados, o húmus de minhoca foi o que resultou em maior desenvolvimento das plântulas.

Palavras-chave: Heliconia bihai, micropropagação, aclimatização, substratos.

\begin{abstract}
Effects of organic fertilizers and substrates on development of micropropagated heliconia plantlets

The efficiency of three different organic substrates (carbonised rice hull, dry and green coir dust) and two fertilizers (Vitasolo® and humus of earthworm), were evaluated in factorial scheme $(3 \times 2)$ at the ratio of 3:1 (v/v) in the acclimatization of plantlets of Heliconia bihai, obtained from in vitro culture. The following pre-defined orthogonal contrasts were set up: coir dust (green or dry) x carbonised rice hull; green coir dust $\mathrm{x}$ dry coir dust; Vitasolo ${ }^{\circledR} \mathrm{x}$ humus of earthworm. After 75 days, height of the plants, diameter of pseudostem, number of leaves and area of the third leaf were evaluated. In relation to all the variables studied, the carbonised rice hull was more efficient than the coir dust (green or dry); there wasn't significant difference between dry or green coir dust; among the tested fertilizers, humus of earthworm was more efficient than Vitasolo®.
\end{abstract}

Keywords: Heliconia bihai, micropropagation, acclimatization, substrates.

\section{(Recebido para publicação em 22 de novembro de 2004 e aceito em 16 de agosto de 2006)}

A demanda atual por plantas ornamentais e flores de corte dos países do primeiro mundo alcança US\$ 90 bilhões por ano, com uma taxa de crescimento estimada da ordem de $12 \%$ ao ano (Lamas, 2002). Segundo dados do Instituto Brasileiro de Floricultura (IBRAFLOR, 2005), o Brasil movimenta, anualmente, cerca de US\$ 1 bilhão no negócio de flores, em uma área cultivada de aproximadamente $5.250 \mathrm{hec}$ tares, gerando cerca de 200.000 postos de trabalho. Trata-se de uma das melhores alternativas de investimento na agricultura, porque demanda pouca área e o ciclo de produção é geralmente curto, permitindo rápido retorno do capital investido. As exportações brasileiras de flores e plantas ornamentais, em 2004 atingiram US\$ 23,5 milhões, valor esse que superou em $20,96 \%$ os resultados obtidos em 2003, confirmando todos os prognósticos sobre a performance con- temporânea do setor exportador da floricultura brasileira.

De acordo com Castro \& Graziano (1997), a saturação do mercado mundial pelas plantas ornamentais tradicionais faz com que haja crescente interesse por parte dos consumidores estrangeiros pelas espécies tropicais. Neste contexto, se destacam as espécies do gênero Heliconia, muito apreciadas em função das suas peculiaridades. Seu excepcional potencial de comercialização no mercado interno e externo se deve à aparência exótica das inflorescências e à grande variação de cores e formas, com produção de flores contínua, em grande quantidade e com alta durabilidade após o corte, apresentando perspectivas promissoras como flores de corte e plantas para paisagismo.

Estas espécies vêm apresentando crescente comercialização no mercado internacional, em função do aumento da área de produção nos países da América Central e da América do Sul, proporcionando uma maior oferta e, consequentemente, a sua divulgação. No Brasil, os estados com maior potencial para o cultivo são Rio de Janeiro, São Paulo, Santa Catarina, Pernambuco, Amazonas e Ceará (Castro, 1995). O Ceará apresenta condições edafoclimáticas favoráveis ao cultivo em todas as estações do ano e os preços da terra e da mão-de-obra são inferiores aos dos demais estados produtores, sendo necessário apenas que se utilize tecnologia apropriada para o aumento da produção (Paiva, 1998).

A propagação comercial das helicônias é geralmente vegetativa, através dos rizomas. Porém, este método conduz à disseminação e ao acúmulo de agentes causais de importantes doenças que são transmitidas entre plantios sucessivos, via rizomas contaminados por 
fungos, bactérias e, principalmente, vírus e nematóides, que dificultam ou impedem a manifestação do verdadeiro potencial produtivo. Isto levou vários países a imporem uma rígida quarentena para a importação de rizomas, principalmente após descobertas de cepas de Pseudomonas solanacearum (Smith) em plantas doentes obtidas a partir de rizomas (Nathan et al., 1992).

Por outro lado, a propagação através de sementes apresenta várias desvantagens em relação à propagação via rizomas. Em geral, produz mudas maiores, de menor valor comercial e manuseio mais difícil, por serem pesadas. As sementes apresentam dormência devido à restrição mecânica, pois o fruto é uma baga com pericarpo duro, que impede a sua germinação. O período para florescimento de mudas propagadas por sementes é muito longo, de 3 a 4 anos. Além disso, nem todas as espécies frutificam e a maioria dos cruzamentos interespecíficos são incompatíveis (Nannetti, 1994).

A micropropagação apresenta-se como alternativa viável para a produção de mudas de helicônia em larga escala e com qualidade genética e fitossanitária, sendo que vários métodos têm sido utilizados. A multiplicação de gemas axilares de rizomas uma técnica eficiente e usual em programas de micropropagação de helicônias (Nathan et al., 1992). Goh et al. (1995) regeneraram plantas desta espécie, através de organogênese direta e indução de calos em explantes retirados da base de plântulas. A cultura de embriões também pode constituir uma interessante aplicação da cultura de tecidos no cultivo de helicônia, permitindo o resgate de embriões oriundos de cruzamentos híbridos, os quais não sobreviveriam na planta-mãe. Esta técnica é utilizada também para reduzir o ciclo fenológico da planta (Hu \& Ferreira, 1998).

A aclimatização das mudas obtidas a partir de métodos de cultivo in vitro é uma fase fundamental para o sucesso da micropropagação, pois este é o momento em que ocorre a transição do heterotrofismo para o autotrofismo, em condições ex vitro (Sciutti \& Morini, 1993). Neste contexto, é fundamental a determinação dos substratos adequados para a aclimatização, os quais devem garantir a manutenção mecânica do sistema radicular, a estabilidade da planta, o suprimento de água e nutrientes e as trocas gasosas entre as raízes e o ar atmosférico (Silveira et al., 2002).

A determinação de substratos alternativos, que sejam viáveis para a aclimatização é de grande relevância, pois o aproveitamento de resíduos da agroindústria em práticas agrícolas representa a solução de problemas sociais e ambientais (Silveira et al., 2002). O pó de casca de coco tem sido recomendado para cultivos de plantas ornamentais, bem como a casca de arroz, também bastante utilizada por floricultores. Estes dois subprodutos são considerados substratos praticamente inertes, que não reagem com os nutrientes da adubação e possuem longa durabilidade, sem alteração de suas características físicas. Como não possuem os nutrientes essenciais para as plantas, devem ser utilizados em combinação com adubos (Carrijo et al., 2002).

A utilização de húmus de minhoca, ou vermicompostagem, é uma opção muito interessante para a agroindústria, pois permite o enriquecimento da matéria orgânica disponível, por meio do aumento na disponibilização de nutrientes, de forma economicamente viável e ambientalmente sustentável (Bakker, 1994). Este adubo é, em média, 70\% mais rico em nutrientes que os húmus convencionais. É rico em microrganismos, com pH neutro, alta retenção de água e mineralização lenta (Longo, 1987; Aquino et al., 1992).

Como citado por Bosa et al. (2003) existem poucos trabalhos que relatam o estudo do substrato na fase de transplante da planta desenvolvida in vitro para as condições ex vitro.

Considerando a escassez de estudos na literatura científica referentes à aclimatização de plântulas das espécies pertencentes ao gênero Heliconia, e a crescente necessidade da utilização de práticas agrícolas sustentáveis e economicamente viáveis, o objetivo deste trabalho foi avaliar a eficiência de adubos e substratos orgânicos no desenvolvimento de mudas de Heliconia bihai, durante a fase de aclimatização.

\section{MATERIAL E MÉTODOS}

O experimento foi conduzido na Embrapa Agroindústria Tropical, em Fortaleza - CE, de outubro/2003 a janeiro/2004. As mudas utilizadas na aclimatização foram obtidas in vitro, mediante oito subcultivos em meio MS (Murashige \& Skoog, 1962) suplementado com 2,0 mg.L $\mathrm{L}^{-1}$ de BAP (6-benzilaminopurina). Estas foram enraizadas em meio MS com 1,0 mg. $\mathrm{L}^{-1}$ de AIB (ácido indolbutírico), em frascos cilíndricos de vidro transparente de $100 \mathrm{~mm}$ de altura e $63 \mathrm{~mm}$ de diâmetro interno, com tampa de polipropileno de rosca, contendo $30 \mathrm{~mL}$ de meio de cultura, sob fotoperíodo de 16 horas e temperatura de $25 \pm 1^{\circ} \mathrm{C}$. Após 30 dias de enraizamento in vitro, as plântulas foram retiradas dos frascos, lavadas e transferidas individualmente para tubetes de polipropileno rígido de 52 $\mathrm{mm}$ de diâmetro interno por $140 \mathrm{~mm}$ de altura. Os tratamentos estudados foram compostos por combinações de três substratos orgânicos com dois adubos, em esquema fatorial $3 \times 2$, na proporção de 3:1 (volume/volume): 1) pó de casca de coco seco $(\mathrm{CS})+$ Vitasolo ${ }^{\circledR}(\mathrm{VS})$ adubo comercial; 2) pó de casca de coco verde $(\mathrm{CV})+$ Vitasolo $\left.{ }^{\circledR} ; 3\right)$ casca de arroz carbonizada $(\mathrm{CAC})+$ Vitasolo $\left.{ }^{\circledR} ; 4\right)$ pó de casca de coco seco + húmus de minhoca (HM); 5) pó de casca de coco verde + húmus de minhoca; 6) casca de arroz carbonizada + húmus de minhoca. O Vitasolo é um adubo natural, cujos compostos orgânicos e minerais são bioquimicamente estabilizados, com matéria orgânica superior a $48 \%$, alta retenção de água, e pH aproximadamente neutro. Este composto é tradicionalmente comercializado no mercado regional, como adubo completo. O pó de casca de coco verde e da casca de coco seco apresentavam, inicialmente, condutividades elétricas em torno de 3,15 , sendo corrigidas, através de lavagens com água, de acordo com Rosa et al. (2001). Foram avaliadas as características químicas e físicas das seis combinações de substratos e adubos, conforme metodologias descritas em Ritas \& Melida (1990). As análises químicas incluíram o pH e os terores de $\mathrm{P}, \mathrm{K}, \mathrm{Ca}$, 
$\mathrm{Mg}, \mathrm{Cu}, \mathrm{Fe}, \mathrm{Mn}, \mathrm{Zn}$ e Na. As análises físicas incluíram a condutividade elétrica (CE), o volume de sólidos (Vs), o volume de poros $(\mathrm{Vp})$, a relação $\mathrm{Vp} / \mathrm{Vs}$, a porosidade total (PT), a capacidade de retenção de água (CRA) e o espaço de aeração (EA).

A aclimatização foi feita em condições de casa de vegetação, com sombreamento de $80 \%$, temperatura de $30+5^{\circ} \mathrm{C}$ e irrigação por nebulização de 30 minutos, três vezes ao dia. Após 75 dias da implantação do experimento, foram avaliadas a porcentagem de sobrevivência; a altura total da planta; o diâmetro do pseudocaule na altura do colo da planta; o número de folhas; e a área da terceira folha, obtida através de um aparelho LICOR, modelo LI-3000. A utilização destas variáveis na avaliação do desenvolvimento das plantas foi realizada de acordo com Matos (2000).

O delineamento experimental foi inteiramente casualizado, com oito repetições, sendo a unidade experimental constituída por cinco mudas. Foram estabelecidos contrastes ortogonais, definidos a priori - $\mathrm{C} 1$ : pó de casca de coco (seco ou verde) x casca de arroz carbo- nizada; C2: pó de casca de coco seco $\mathrm{x}$ pó de casca de coco verde; e C3: Vitasoloâ x húmus de minhoca. Os dados obtidos foram submetidos à análise de variância e as médias comparadas através do teste $\mathrm{F}$, a 1 e $5 \%$ de probabilidade.

\section{RESULTADOS E DISCUSSÃO}

Em todos os tratamentos utilizados na aclimatização de $H$. bihai, a sobrevivência das plantas foi de $100 \%$.

As características físicas e químicas das seis combinações de substratos e adubos encontram-se, respectivamente, nas Tabelas 1 e 2. A utilização dos contrastes ortogonais na avaliação do experimento, apresentados na Tabela 3, permitiu formular questões fundamentais e, ao mesmo tempo, interpretar objetivamente os resultados obtidos.

As maiores médias para todas as variáveis estudadas, representado o maior desenvolvimento vegetal, foram obtidas na combinação de casca de arroz carbonizada com húmus de minhoca: 32,67 cm de altura da planta, 19,73 mm de diâmetro do pseudocaule, núme-

Tabela 1. Características físicas das combinações dos adubos e substratos empregados na aclimatização de H. bihai. Fortaleza, Embrapa Agroindústria Tropical, 2004.

\begin{tabular}{lcccccc}
\hline Substratos & $\begin{array}{c}\text { Vs } \\
\left(\mathbf{c m}^{3} \cdot \mathbf{d m}^{-3}\right)\end{array}$ & $\begin{array}{c}\mathbf{V p} \\
\left(\mathbf{c m}^{3} \cdot \mathbf{d m}\right.\end{array}$ & Vp/Vs & PT (\%) & CRA (\%) & EA (\%) \\
\hline CS + VS & 200 & 800 & 4,0 & 80 & 57 & 23 \\
CV + VS & 240 & 760 & 3,2 & 76 & 40 & 36 \\
CAC + VS & 300 & 700 & 2,3 & 70 & 50 & 20 \\
CS + HM & 260 & 740 & 2,8 & 74 & 57 & 17 \\
CV + HM & 250 & 750 & 3,0 & 75 & 44 & 31 \\
CAC + HM & 280 & 720 & 2,6 & 72 & 51 & 21 \\
\hline
\end{tabular}

CS: pó de casca de coco seco; CV: pó de casca de coco verde; CAC: casca de arroz carbonizada; VS: vitasolo; HM: húmus de minhoca. ro de folhas por planta de 9,99 e área foliar de 48,32 $\mathrm{cm}^{2}$ (Tabela 3). Esta combinação apresenta relação $\mathrm{Vp} / \mathrm{Vs}$ de 2,6 , porosidade total de $72 \%$, capacidade de retenção de água de $51 \%$ e espaço de aeração de $21 \%$ (Tabela 1 ).

O menor desenvolvimento vegetal, em todas as variáveis, foi obtido na combinação de coco seco e Vitasolo ${ }^{\circledR}$, na qual a relação $\mathrm{Vp} / \mathrm{Vs}(4,0)$, a porosidade total $(80 \%)$ e a capacidade de retenção de água $(57 \%)$, foram as maiores obtidas em todas as combinações. Por outro lado, valores inferiores na relação $\mathrm{Vp} / \mathrm{Vs}(2,3)$, na porosidade total $(70 \%)$ e na capacidade de retenção de água (50\%) foram observados na combinação de casca de arroz e Vitasolo ${ }^{\circledR}$, que também resultou em menor desenvolvimento das plantas.

Com relação ao espaço de aeração, valores abaixo do obtido na combinação de casca de arroz e húmus de minhoca $(21 \%)$ foram observados nas combinações de casca de arroz e Vitasolo, e coco seco e húmus de minhoca, as quais apresentaram espaço de aeração de 20 e $17 \%$, respectivamente. Por outro lado, as combinações coco seco e Vitasolo ${ }^{\circledR}$, coco verde e húmus de minhoca, e coco verde e Vitasolo ${ }^{\circledR}$, apresentaram espaço de aeração de 23 , 31 e $36 \%$, respectivamente, e também resultaram em menor desenvolvimento vegetal, em termos gerais.

Na Tabela 2 observa-se, com relação às características químicas, que a condutividade elétrica das combinações coco seco e Vitasoloâ $\left(2,07 \mathrm{dS} \cdot \mathrm{m}^{-1}\right)$ e coco seco e húmus de minhoca $(2,12$ $\mathrm{dS} . \mathrm{m}^{-1}$ ) apresentam valores acima dos considerados ideais para mudas de plantas ornamentais segundo Ballester-Ol-

Tabela 2. Características químicas das combinações dos adubos e substratos empregados na aclimatização de $H$. bihai. Fortaleza, Embrapa Agroindústria Tropical, 2004.

\begin{tabular}{|c|c|c|c|c|c|c|c|c|c|c|c|}
\hline Substratos & $\begin{array}{c}C E \\
\left(d S . m^{-1}\right)\end{array}$ & $\mathrm{pH}$ & $P(p p m)$ & $\begin{array}{c}\mathrm{K} \\
(\mathrm{mmolc} . \\
\left.\mathrm{dm}^{-3}\right)\end{array}$ & $\begin{array}{c}\mathrm{Ca} \\
(\mathrm{mmolc} \\
\left.\mathrm{dm}^{-3}\right)\end{array}$ & $\begin{array}{c}\mathrm{Mg} \\
\left(\mathrm{mmolc}^{-}\right. \\
\left.\mathrm{dm}^{-3}\right)\end{array}$ & $\begin{array}{c}\mathrm{Cu} \\
\left(\mathrm{mg} \cdot \mathrm{dm}^{-3}\right)\end{array}$ & $\begin{array}{c}\mathrm{Fe} \\
\left(\mathrm{mg} \cdot \mathrm{dm}^{-3}\right)\end{array}$ & $\begin{array}{c}\mathrm{Mn} \\
\left(\mathrm{mg} \cdot \mathrm{dm}^{-3}\right)\end{array}$ & $\begin{array}{c}\mathrm{Zn} \\
\left(\mathrm{mg} \cdot \mathrm{dm}^{-3}\right)\end{array}$ & $\begin{array}{c}\mathrm{Na} \\
\left(\mathrm{mmolc} . \mathrm{dm}^{-3}\right)\end{array}$ \\
\hline $\mathrm{CS}+\mathrm{VS}$ & 2,07 & 6,14 & 26,85 & 10,00 & 1,28 & 1,21 & 0,03 & 0,62 & 0,05 & 0,05 & 8,80 \\
\hline$C V+V S$ & 1,16 & 6,40 & 27,24 & 5,40 & 1,32 & 0,65 & 0,03 & 2,29 & 0,02 & 0,04 & 5,70 \\
\hline$C A C+V S$ & 1,46 & 6,82 & 50,62 & 10,20 & 1,15 & 0,73 & 0,04 & 0,37 & 0,14 & 0,08 & 4,00 \\
\hline $\mathrm{CS}+\mathrm{HM}$ & 2,12 & 6,57 & 91,25 & 11,80 & 1,34 & 1,47 & 0,02 & 0,43 & 0,03 & 0,03 & 8,60 \\
\hline $\mathrm{CV}+\mathrm{HM}$ & 0,90 & 7,08 & 78,11 & 3,50 & 1,70 & 2,42 & 0,10 & 0,04 & 0,03 & 0,01 & 3,70 \\
\hline $\mathrm{CAC}+\mathrm{HM}$ & 1,21 & 7,28 & 77,91 & 7,50 & 1,44 & 2,67 & 0,02 & 0,02 & 0,01 & 0,01 & 1,71 \\
\hline
\end{tabular}

CS: pó de casca de coco seco; CV: pó de casca de coco verde; CAC: casca de arroz carbonizada; VS: vitasolo; HM: húmus de minhoca. 
Tabela 3. Comparações entre grupos de médias pelos contrastes ortogonais para as variáveis avaliadas aos 75 dias de aclimatização de $H$. bihai, em diferentes combinações de adubos e substratos orgânicos ${ }^{1}$. Fortaleza, Embrapa, 2004.

\begin{tabular}{|c|c|c|c|c|c|c|c|c|}
\hline Contrastes $^{2}$ & CS+VS & $C V+V S$ & CAC+VS & $\mathrm{CS}+\mathrm{HM}$ & $\mathrm{CV}+\mathrm{HM}$ & $\mathrm{CAC}+\mathrm{HM}$ & Total & QM \\
\hline \multicolumn{9}{|c|}{ Altura $(\mathrm{cm})$} \\
\hline $\mathrm{C} 1$ & $+17,44$ & $+22,78$ & $-2(21,29)$ & $+22,76$ & $+22,95$ & $-2(32,67)$ & $-21,99$ & $125,84^{* *}$ \\
\hline $\mathrm{C} 2$ & $+17,44$ & $-22,78$ & & $+22,76$ & $-22,95$ & & $-5,53$ & $23,89^{\text {ns }}$ \\
\hline C3 & $+17,44$ & $+22,78$ & $+21,29$ & $-22,76$ & $-22,95$ & $-32,67$ & $-16,87$ & $49,34^{* *}$ \\
\hline \multicolumn{9}{|c|}{ Diâmetro do pseudocaule (mm) } \\
\hline $\mathrm{C} 1$ & $+11,27$ & $+16,42$ & $-2(15,64)$ & $+17,60$ & $+15,68$ & $-2(19,73)$ & $-9,77$ & $24,87^{* *}$ \\
\hline $\mathrm{C} 2$ & $+11,27$ & $-16,42$ & & $+17,60$ & $-15,68$ & & $-3,23$ & $8,16^{\text {ns }}$ \\
\hline C3 & $+11,27$ & $+16,42$ & $+15,64$ & $-17,60$ & $-15,68$ & $-19,73$ & $-9,68$ & $16,33^{* *}$ \\
\hline \multicolumn{9}{|c|}{$N^{\circ}$ de folhas } \\
\hline $\mathrm{C} 1$ & $+6,97$ & $+7,26$ & $-2(9,14)$ & $+9,22$ & $+8,60$ & $-2(9,99)$ & $-6,21$ & $10,09^{* *}$ \\
\hline $\mathrm{C} 2$ & $+6,97$ & $-7,26$ & & $+9,22$ & $-8,60$ & & $+0,33$ & $0,09^{\text {ns }}$ \\
\hline $\mathrm{C} 3$ & $+6,97$ & $+7,26$ & $+9,14$ & $-9,22$ & $-8,60$ & $-9,99$ & $-4,44$ & $3,41^{*}$ \\
\hline \multicolumn{9}{|c|}{ Área foliar $\left(\mathrm{cm}^{2}\right)$} \\
\hline $\mathrm{C} 1$ & $+13,68$ & $+23,17$ & $-2(24,94)$ & $+33,98$ & $+29,39$ & $-2(48,32)$ & $-46,30$ & $557,92^{* *}$ \\
\hline $\mathrm{C} 2$ & $+13,68$ & $-23,17$ & & $+33,98$ & $-29,39$ & & $-4,90$ & $18,80^{\text {ns }}$ \\
\hline C3 & $+13,68$ & $+23,17$ & $+24,94$ & $-33,98$ & $-29,39$ & $-48,32$ & $-49,90$ & $432,26^{* *}$ \\
\hline
\end{tabular}

${ }^{1} \mathrm{CS}$ : pó de casca de coco seco; CV: pó de casca de coco verde; CAC: casca de arroz carbonizada; VS: Vitasolo®; HM: húmus de minhoca. ${ }^{2} \mathrm{C} 1$ : pó de casca de coco (seco ou verde) x casca de arroz carbonizada; C2: pó de casca de coco seco x pó de casca de coco verde; e C3: Vitasolo® $\mathrm{x}$ húmus de minhoca. ${ }^{\text {ns }}$ Não significativo. * e ** Significativo a $5 \%$ e $1 \%$ de probabilidade pelo teste $\mathrm{F}$.

mos (apud Bosa et al., 2003), que são de 0,75 a 2,00 dS.m ${ }^{-1}$, sendo que as demais combinações encontram-se nesta faixa. É importante observar que a combinação arroz carbonizado e húmus de minhoca, que resultou no maior desenvolvimento das plantas, apresentou condutividade elétrica de 1,21 dS.m-1, situando-se próximo à mediana da faixa considerada ideal por este autor.

Quanto ao pH, apenas as combinações coco seco e Vitasoloâ, e coco verde e Vitasolo encontram-se dentro da faixa considerada ideal para o cultivo de helicônias (5,5 a 6,5), de acordo com Leitão (2006). A combinação de casca de arroz e húmus de minhoca apresentou $\mathrm{pH}$ de 7,28, levemente básico em relação ao preconizado pela autora.

Por meio do primeiro contraste pode-se verificar, na Tabela 3, em relação a todas as variáveis observadas, que a casca de arroz apresentou valores significativamente superiores aos obtidos com a utilização do pó da casca de coco, verde ou seco. A eficiência da casca de arroz carbonizada em compostos foi comprovada por Maciel et al. (2002), que trabalhou com aclimatização de porta-enxertos micropropagados de macieira, observando o enraizamento e, consequentemente, o desenvolvimento das plântulas nesta fase. Outras combinações foram testadas por Rodrigues et al. (2004), que utilizaram 11 compostos de diferentes proporções de casca de arroz carbonizada, areia, húmus e terra na aclimatização de mudas micropropagadas de bromélia-imperial (Alcantarea imperialis), e observaram que a combinação de casca de arroz e areia $(1: 1, \mathrm{v} / \mathrm{v})$ foi mais eficiente na indução do desenvolvimento das mudas. Couto et al. (2003) avaliaram o efeito de casca de arroz carbonizada em combinações com húmus, solo e esterco; com húmus e solo; com húmus; e com Plantmaxâ, na aclimatização de plantas micropropagadas de Prunus cerasifera, constatando que a combinação de casca de arroz e Plantmaxâ foi o melhor substrato, em relação à sobrevivência das plantas e ao seu crescimento.

Nos tratamentos onde utilizou-se casca de coco verde ou seco como substrato orgânico, não foram observadas diferenças estatísticas para nenhuma das variáveis analisadas, o que pode ser verificado por meio dos quadrados médios obtidos no segundo contraste. Estes resultados não estão de acordo com os obtidos por Terceiro Neto et al. (2004), que obtiveram crescimento significativamente mais expressivo com a utilização de coco verde em relação ao coco seco, em todas as variáveis avaliadas, na aclimatização de plântulas de violeta africana (Saintpaulia ionantha Wendl.). Por outro lado, Bezerra et al. (2001) compararam o coco verde e o seco como substratos para enraizamento e produção de massa fresca e seca em estacas de crisântemo e concluíram que o coco seco é mais adequado para esta finalidade. Correia et al. (2003), avaliaram o efeito da utilização de pó de coco verde e seco no desenvolvimento de mudas de cajueiro anão precoce, e também não encontraram diferenças significativas entre estes substratos em relação às variáveis estudadas.

Os tratamentos contendo húmus de minhoca resultaram em valores significativamente superiores aos obtidos nos tratamentos com Vitasoloâ, em relação a todas as variáveis estudadas. Correia et al. (2001), estudando o efeito de diferentes substratos e adubos na formação de porta-enxertos de gravioleira, observaram que o húmus de minhoca caracteriza-se por proporcionar um adequado desenvolvimento vegetativo e do sistema radicular, além de funcionar como eficiente fonte de matéria orgânica para as plantas. 
Bosa et al. (2003) avaliaram o crescimento de mudas de Gipsophila paniculata, em diferentes substratos, durante a aclimatização. Seus resultados indicaram que os substratos perlita + turfa e casca de pinus + perlita + turfa são adequados nesta fase, provavelmente devido ao fato de apresentarem alta capacidade de retenção de água, pois a disponibilidade de água otimiza a aclimatização desta espécie. A aclimatização de plântulas de violetaafricana (Saintpaulia ionantha Wendl.) foi estudada por Maciel et al. (2000), que obtiveram uma taxa de $100 \%$ de sobrevivência, em várias combinações de areia e composto orgânico, sendo que a proporção de 1:1 resultou em maior acúmulo de matéria fresca. Weber et al. (2003) estudaram o crescimento e o acúmulo de nutrientes em mudas micropropagadas de abacaxizeiro em tubete, e concluíram que a mistura de casca de arroz carbonizada, vermiculita e vermicomposto (1:1:1) constitui alternativa para a aclimatização de mudas. A mistura de casca de arroz carbonizada e pó de casca de coco $(1: 1)$ resultou em baixo desempenho das mudas, o que os autores atribuem a certas características do pó de casca de coco, como má agregação física, baixa retenção de água e limitação nutricional.

Um recente trabalho relata a aclimatização de Heliconia bihai em areia lavada, vermiculita (textura média) e PlantMax ${ }^{\circledR}$ Horticultura, a pleno sol e sob $30,40,50,60,70$ e $80 \%$ de sombreamento. Avaliou-se a sobrevivência de plântulas micropropagadas durante 28 dias após a transferência para as condições ex vitro. As maiores taxas de sobrevivência (95\%) foram obtidas com a utilização de areia lavada e PlantMax ${ }^{\circledR}$ Horticultura, sob 80 e $70 \%$ de sombreamento, respectivamente. Os autores não consideram recomendável a utilização de vermiculita para a aclimatização desta espécie, uma vez que a maior taxa de sobrevivência que obtiveram com este substrato foi de $32,5 \%$, com $80 \%$ de sombreamento (Rodrigues et al., 2005).

Com base nos resultados obtidos neste trabalho, pode-se concluir que a aclimatização de Heliconia bihai pode ser efetuada à temperatura de $30+5^{\circ} \mathrm{C}$, irrigação por nebulização de $30 \mathrm{minu}$ tos, três vezes ao dia, com sombreamento de $80 \%$, recomendandose como substrato a combinação de casca de arroz carbonizada com húmus de minhoca, na proporção de 3:1.

\section{AGRADECIMENTOS}

Ao CNPq pela concessão de bolsas.

\section{REFERÊNCIAS}

AQUINO AM; ALMEIDA DL; SILVA VF. 1992 Utilização de minhocas na estabilização de resíduos orgânicos: vermicompostagem. Rio de Janeiro: Embrapa/CNPBS. 12p. (Comunicado Técnico, 8)

BAKKER AP. 1994. Efeito do húmus de minhoca e da inoculação do fungo micorrízico arbuscular Glomus macrocarpum Tul. \& Tul. sobre o desenvolvimento de mudas de cajueiro anão-precoce (Anacardium occidentale L.). . 60p. Fortaleza: Universidade Federal do Ceará (Tese)

BEZERRA FC; ROSA MF; BRÍGIDO AKL; NORÕES ERV. 2001. Utilização de pó de coco como substrato de enraizamento para estacas de crisântemo. Revista Brasileira de Horticultura Ornamental 7: 129-134.

BOSA N; CALVETE EO; KLEIN VA; SUZIN M. 2003. Crescimento de mudas de gipsofila em diferentes substratos. Horticultura Brasileira 21: 514-519.

CARRIJO OA; LIZ RS; MAKISHIMA N. 2002. Fibra da casca do coco verde como substrato agrícola. Horticultura Brasileira 20: 533-535.

CASTRO CEF. 1995. Helicônias para exportação: aspectos técnicos da produção. Brasília: Embrapa, coleção FRUPEX. 44p.

CASTRO CEF; GRAZIANO TT. 1997. Espécies do gênero Heliconia (Heliconiaceae) no Brasil. Revista Brasileira de Horticultura Ornamental 3: 15-28.

CORREIA D; CAVALCANTI JÚNIOR AT; COSTA AMG. 2001. Alternativas de substratos para a formação de porta-enxertos de gravioleira (Annona muricata) em tubetes. Fortaleza: Embrapa Agroindústria Tropical. 3p. (Comunicado Técnico, 67).

CORREIA D; ROSA MF; NORÕES ERV; ARAÚJO FB. 2003. The use of coir dust for preparation of substrates for grafted dwarf cashew seedlings. Revista Brasileira de Fruticultura 25: 557-558.

COUTO M; WAGNER JÚNIOR A; QUEZADA AC. 2003. Efeito de diferentes substratos durante a aclimatização de plantas micropropagadas do porta-enxerto Mirabolano 29C (Prunus cerasifera EHRH) em casa de vegetação. Revista Brasileira de Agrociência 9: $125-128$.
GOH CJ; NATHAN MJ; KUMAR PP. 1995. Direct organogenesis and induction of morphogenic callus through thin section culture of Heliconia psittacorum. Scientia Horticulturae 62: 113-120.

HU CY; FERREIRA AG. 1998. Cultura de embriões. In: TORRES AC; CALDAS LS; BUSO JA. Cultura de Tecidos e Transformação de Genética de Plantas 1. Brasília: Embrapa-SPI/ Embrapa-CNPH. p. 371-393.

IBRAFLOR. Análise conjuntural das exportações de flores e plantas ornamentais do Brasil (janeiro a dezembro de 2004). Disponível em http://www.ibraflor.com.br. Acessado em: 01 agosto 2005.

LAMAS AM. 2002. Floricultura Tropical: técnicas de cultivo e pós-colheita de flores e folhagens. Fortaleza: Instituto Frutal. 135p.

LEITÃO APS. 2006. Produção de Flores Tropicais. Holambra-SP: FLORTEC. 38p.

LONGO AD. 1987. Minhoca: de fertilizadora do solo a fonte alimentar. São Paulo: Ícone. 79p.

MACIEL ALR; SILVA AB; PASQUAL M. 2000. Aclimatação de plantas de violeta africana (Saintpaulia ionantha Wendl.) obtidas in vitro: efeitos do substrato. Ciência e Agrotecnologia 24: 9-12.

MACIEL SC; VOLTOLINI JA; PEDROTTI EL. 2002. Enraizamento ex vitro e aclimatização do porta-enxerto de macieira Marubakaido micropropagado. Revista Brasileira de Fruticultura. Disponível em http://www.scielo.br/ scielo.php?script=sci_arttext\&pid=S0100294520020002000003. Acessado em: 25 janeiro 2006.

MATOS RMB.2000. Ecologia microbiana com ênfase no estudo dos fungos micorrízicos arbusculares em plantas micropropagadas de bananeira (Musa spp.). Rio de Janeiro: UFRRJ. 253p. (Tese).

MURASHIGE T; SKOOG FA. 1962. Revised medium for rapid growth and bioassays with tobacco tissue cultures. Physiologia Plantarum 25: 473-497.

NANNETTI DC. 1994. Utilização da cultura de tecidos vegetais na micropropagação de Heliconia sp. Lavras: UFLA. 106p. (Dissertação).

NATHAN MJ; GOH CJ; KUMAR PP. 1992. In vitro propagation of Heliconia psittacorum by bud culture. HortScience 27: 450-452.

PAIVA WO. 1998. Cultura de Helicônias. Fortaleza: Embrapa-CNPAT. 20p. (EmbrapaCNPAT, Circular Técnica, 2)

RITAS JL; MELIDA JL.1990. El diagnostico de suelos y plantas: metodos de campo $y$ laboratorio. 4 ed. Madri: Mundi-Prensa. 363p.

RODRIGUES PHV; LIMA AMLP; AMBROSANO GMB; DUTRA MFB. 2005. Acclimatization of micropropagated Heliconia bihai (Heliconiaceae) plants. Scientia Agricola 62: 299-301.

RODRIGUES TM; PAIVA PDO; RODRIGUES CR; CARVALHO JG; FERREIRA CA; PAIVAR.2004. Desenvolvimento de mudas de bromélia-imperial (Alcantarea imperialis) em diferentes substratos. Ciência e Agrotecnologia 28: 757-763. 
ROSA MF; BEZERRA FC; ARAÚJO FBS NORÕES VER. 2001. Utilização do pó da casca de coco verde na germinação de alface hidropônico. Horticultura Brasileira 19: 294.

SCIUTTI R; MORINI S. 1993. Effect of relative humidity in in vitro culture on some growth characteristics of a plum rootstock during shoot proliferation and rooting and on plantlet survival. Advances in Horticultural Science 7: 153-156.

SILVEIRA EB; RODRIGUES VJLB; GOMES AMA; MARIANO RLR; MESQUITA JCP 2002. Pó de coco como substrato para produção de mudas de tomateiro. Horticultura Brasileira 20: 211-216.
TERCEIRO NETO CPC; HERNANDEZ FFF; BEZERRA FC; SOUSA RF; CAVALCANTI MLF. 2004. Efeito de diferentes substratos na aclimatização "ex vitro" de mudas de violeta africana (Saintpaulia ionantha Wendl.). Revista de Biologia e Ciências da Terra 4: 2. Disponível em http://www.uepb.edu.br/eduep/ rbct/sumarios/pdf/violetaafricana2.pdf. Acessado em: 06 junho de 2006.
WEBER OB; CORREIA D; SILVEIRA MRS; CRISÓSTOMO LA; OLIVEIRA EM; SÁ EG. 2003. Efeito da bactéria diazotrófica em mudas micropropagadas de abacaxizeiros Cayenne Champac em diferentes substratos. Pesquisa Agropecuária Brasileira 38: 689696 